the diabetes. This type of resistance may occur at any age, but is more frequent in the fifth decade ; the typical onset is within a year of the start (or restart) of insulin treatment. This type of resistance responds well to corticosteroid treatment. Resistance with a requirement between 200 and 300 units is seldom of the antibody type, and it is usual for associated disease or endocrine disturbance to be present. A few patients with high antibody titres were found in this group; most were seen after spontaneous remission from an episode of resistance requiring higher dosage. In the intermediate range of resistance the coexistence of increased antibody formation with other factors was a common finding. It is possible that in some cases an increase in insulin dosage for the treatment of a metabolic disturbance may stimulate antibody formation and lead to a more severe state of resistance.

\section{Summary}

A series of 41 cases of insulin resistance is reviewed; this comprises 28 new cases and 13 previously reported cases which have been followed up.

The clinical features of insulin resistance are considered in relation to age, sex, duration of diabetes, interruption in insulin therapy, allergy, and associated diseases.

The serum of all patients was examined for insulin antibodies by passive cutaneous anaphylaxis (P.C.A.) and in some cases also by haemagglutination. P.C.A. antibody was found in 29 of the 41 cases.

Treatment with corticosteroids is almost always successful in insulin resistance associated with P.C.A. antibodies and unsuccessful when the P.C.A. test is negative.

When the daily insulin requirement exceeds 300 units the insulin antibody titre is usually high and associated pathological conditions are uncommon. Patients whose requirements are less than 300 units more of ten give negative P.C.A. tests and show evidence of associated disease.

ADDENDUM.-Since the completion of this paper we have seen five further cases. In three of the patients who were P.C.A.-positive insulin resistance was successfully treated with prednisone. One patient who had a positive P.C.A. test failed to respond to prednisone, and one in whom the resistance was associated with pregnancy, but whose P.C.A. test was negative, responded well in the first pregnancy, but not in the second.

\section{REFERENCES}

Arquilla, E. R., and Stavitsky, A. B. (1956). 7. clin. Invest., 35, 458 Berson, S. A., and Yalow, R. S. (1957). Diabetes, 6, 402. Bauman, A., Rothschild, M. A., and Newerly, K. (1956). clin. Invest., 35, 170 .

Colwell, A. R., and Weiger, R. W. (1956). F. Lab. clin. Med., 47, 844

Field, J. B., and Stetten, D. (1956). Amer. F. Med., 21, 339

Glen, A., and Eaton, J. C. (1938). Quart. f. Med., 7, 271.

Hubble, D. (1954). Brit. med. $7 ., 2,1022$.

Jones, V. E. (1963). The Immunological Response to Exogenous Insulin Ph.D. Thesis, London.

Ph.D. Thesis, London.
Joslin, E. P., Root, H. F., White, P., and Marble, A. (1959). The Treatment of Diabetes Mellitus, 10th ed., p. 145. Philadelphia.

Kalkhoff, R., Schalch, D. S., Walker, J. L., Beck, P., Kipnis, D. M., and Daughaday, W. H. (1964). Trans. Ass. Amer. Phycns, 77, 270.

Lawrence, R. D. (1946). Lancet, 1, 724.

Lowell, F. C. (1942). Proc. Soc. exp. Biol. (N.Y.), 50, 167.

- (1944). 7. clin. Invest., 23, 233.

Oakley, W., Field, J. B., Sowton, G. E., Rigby, B., and Cunliffe, A. C (1959). Brit, med. \% Sowton,

Root, H. F. (1929). New Engl. F. Med., 201, 201.

Root, H. F. (1929). New Engl. W. Russell, R. O., and Marble, A. (1965)

Shipp, J. C., Cunningham, R. W.,

Smelo, L. S. (1948). Proc. Amer. Diabetes Ass., 8, 75.

Vallance-Owen, J., Dennes, E., and Campbell, P. N. (1958). Lancet, 2. 336.

Yankelowitch, T., Massry, S., and Gitter, S. (1956). Diabetes, 5, 457.

Young, F. G. (1937). Lancet, 2, 372.

\title{
Effects of Cooling on the Safety of Premixed Gases
}

\author{
J. SELWYN CRAWFORD,* M.B., CH.B., F.F.A. R.C.S. ; D. B. ELLIS, † M.B., F.F.A. R.C.S. \\ D. W. HILL, $\ddagger$ M.SC., PH.D., F.INST.P., F.I.E.E. ; J. P. PAYNE, $§$ M.B., F.F.A. R.C.S., D.A.
}

Brit.med. F., 1967, 2, 138-142

The quest for an efficient and practicable method of providing the obstetric patient with nitrous oxide in a non-hypoxic mixture was prompted by the observation that some of the standard gas-and-air equipment in current use delivered considerably less than $10 \%$ oxygen (Cole and Nainby-Luxmore, 1962; Nainby-Luxmore, 1964 ; Moir and Bisset, 1965). Recently efforts have been made to satisfy this demand by providing cylinders containing a mixture of nitrous oxide and oxygen which, when combined with a suitable reducing valve, will deliver a constant proportion of oxygen (Tunstall, 1961). Later Tunstall (1963) and Gale, Tunstall, and Wilton-Davies (1964) described the limits of safety involved in the use of such a system in obstetrics. Recently apparatus designed by the British Oxygen Company has undergone limited clinical trial in both domiciliary and hospital practice, and has been approved by the Central Midwives Board for use by midwives (Lancet, 1965). Cole (1964), however, has produced evidence to suggest

* Deputy Director and Senior Leverhulme Fellow.

+ Dräger Research Fellow.

- Senior Lecturer in Medical Physics.

British Oxygen Professor of Anaesthesia.

Research Department of Anaesthetics, Royal College of Surgeons of England, London W.C.2. that the use of premixed gases is more hazardous than had been believed. His observations on the response of premixed gases to cold and some apparent anomalies in the published data on the influence of temperature change (Tunstall, 1963 ; Gale et al., 1964) invited further investigation. Accordingly, the present study was undertaken.

\section{Material and Methods}

The primary objective of the investigation was to study the effect of cold upon the composition of the gas mixture obtained from a cylinder during the entire period of emptying.

Eighty cylinders containing a $50 / 50 \%$ nitrous oxide and oxygen mixture were studied. Of the cylinders studied 60 were small and contained 500 litres of gas mixture; the remaining 20 large cylinders contained 2,000 litres. On each occasion the cylinder was full at the beginning of the formal " run," which was concluded only when the cylinder had been completely emptied.

Storage and Cooling.-Sixty-five cylinders lying horizontally were cooled for between 12 and 72 hours in one of two ways. 
A cold-storage room in which the temperature was maintained constantly at $-20^{\circ} \mathrm{C}$. was used on 47 occasions. The remaining 18 cylinders were cooled in a laboratory refrigerator, and the minimum temperature during the period of cooling was recorded over a range from $0^{\circ} \mathrm{C}$. to $-15^{\circ} \mathrm{C}$.

Emptying the Cylinder.-A respiratory simulator (Hill, Hook, and Bell, 1961) provided demand emptying of the cylinder through an Entonox demand-valve. The simulator and the demand-valve were connected by corrugated tubing and a Ruben unidirectional valve. Settings on the simulator provided a wide range of respiratory rates and tidal volumes. In most instances a rate between 26 and 30 per minute was chosen, and the cylinder was emptied continuously. On a few occasions the intermittent form of emptying was employed to simulate more closely the events of labour: the simulator was run (usually at 45 per minute) for one minute, and then disconnected from the cylinder for a rest period of two or three minutes. Throughout the study a tidal volume of 1 litre was employed. Cylinders were held either vertically or horizontally during emptying, the position remaining unchanged once the run had been started. On no occasion was frost or dew observed on the cylinder at the start of emptying.

Gas Analysis.-Incorporation of a T-piece arrangement in the tube leading from the demand-valve enabled a sample of the emergent mixture to be drawn through a Beckman oxygen analyser, previously checked against a Haldane apparatus. A minute-to-minute record of the composition of the mixture from the cylinder was obtained in this way. It was confirmed by experiment that even when extremely cold gas was sampled $\left(-60^{\circ} \mathrm{C}\right.$.) the sample was at room temperature when it reached the analyser.

Temperature Measurements.-With the use of previously calibrated thermocouples, temperatures were measured at the base of the cylinder, on the casing covering the spring of the demand-valve, and from within the stream of the emergent gas mixture approximately 5 in. $(12.5 \mathrm{~cm}$.) from the exit port of the demand-valve. In most instances the cylinders were allowed to warm spontaneously in the laboratory (room temperature 20$28^{\circ}$ C.) to a preselected temperature. Sixteen cylinders were warmed by being placed vertically in water (temperature 24$35^{\circ}$ C.) to a depth of $15 \mathrm{in}$. (38 cm.) for exactly five minutes.

Agitation.-Formal agitation of a cylinder, as distinct from the shaking it received during carriage to the bench, consisted of slow inversion three times; but on three occasions this was increased to six times and once to 20 times.

Meteorological Data.-Information regarding the monthly minimum temperatures recorded in parts of the United Kingdom during 1961-5 was extracted from data provided by the meteorological office.

\section{Results}

\section{Composition of the Emergent Mixture}

The emergent mixture from 70 cylinders was analysed; the method of emptying did not appear to influence its composition.

Throughout 36 runs the composition of the mixture remained virtually stable, and provided a measure of the accuracy with which the cylinders had been filled by the manufacturer (Fig. 1). During the remaining 34 runs the issuing mixture was not constant. In these runs a relatively high percentage of oxygen was present initially, but as emptying proceeded the concentration of oxygen gradually fell. The rate of fall varied from one cylinder to another, and was more marked in the vertical than in the horizontal position (Fig. 2). This phenomenon can be explained by partial separation of the components of the mixture.

Of the 35 cylinders cooled to $-20^{\circ} \mathrm{C}$. allowed to rewarm in the ambient air, and agitated, five were large and 30 were small. Cylinder size, however, seemed not to influence the findings.
Evidence of separation was obtained in 23 cylinders. In 12 there was no evidence of separation of nitrous oxide from oxygen; in these the composition of the mixture remained stable throughout the run. The relation between the degree to which a cylinder was rewarmed and the extent to which the mixture was rendered once more homogeneous is indicated

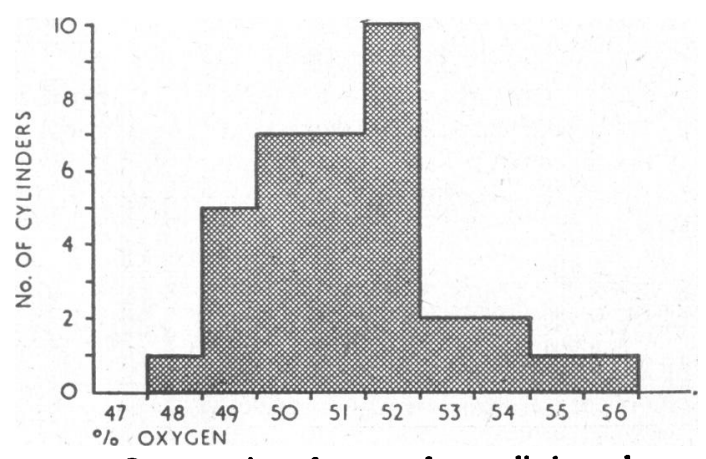

Fig. 1.-Concentration of oxygen from cylinders whose emergent gas mixture remained virtually constant

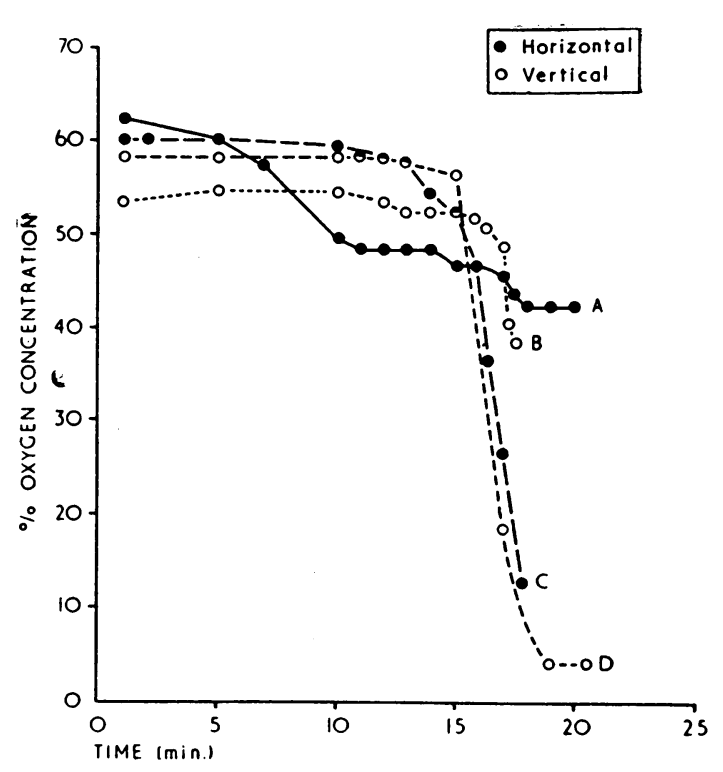

FIG. 2.-Showing changing oxygen percentage in the emergent mixture from $5001.50 / 50 \mathrm{~N}, \mathrm{O} / \mathrm{O}_{2}$ cylinders in vertical or horizontal positions. The cylinders had been cooled overnight at $-20^{\circ} \mathrm{C}$. Cylinder A was rewarmed in water at $35^{\circ} \mathrm{C}$. until the surface temperature of the base of the cylinder was $28.4^{\circ} \mathrm{C}$.; it was not agitated. The other cylinders were allowed to rewarm in room air $\left(20-22^{\circ} \mathrm{C}\right.$.) to temperatures of $3.3^{\circ}$ C. (cylinder B), $-6.3^{\circ}$

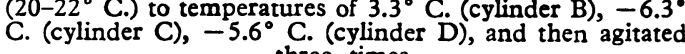
three times.

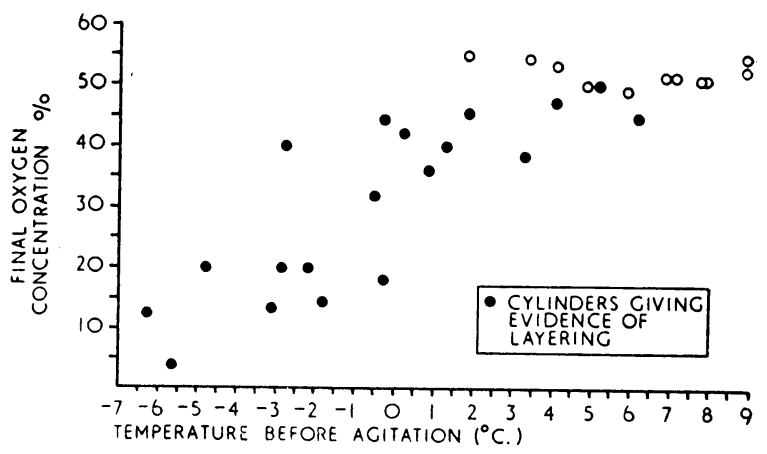

FIG. 3.-Data from 30 500-litre cylinders which were stored for at least an overnight period at $-20^{\circ} \mathrm{C}$., then allowed to rewarm in the ambient air to a preselected temperature, and inverted three times before the run was started. The concentration of oxygen in the emergent mixture delivered just as the cylinder emptied is plotted against this temperature. The solid points indicate those cylinders in which evidence of layering was obtained. 
in Fig. 3, in which the data derived from the 30 small cylinders in this group are plotted. A homogeneous mixture was consistently obtained only from those six cylinders which had been rewarmed to at least $7^{\circ} \mathrm{C}$. Five of the 10 cylinders rewarmed to between 1.9 and $6.3^{\circ} \mathrm{C}$. showed evidence of separation, and all 14 cylinders rewarmed to less than $1.9^{\circ} \mathrm{C}$. showed evidence of separation. Three of the 18 cylinders cooled in the laboratory refrigerator to $-15^{\circ} \mathrm{C}$., $-10^{\circ} \mathrm{C}$., and $-8^{\circ} \mathrm{C}$. respectively also showed evidence of separation.

Twelve cylinders were cooled to $-20^{\circ} \mathrm{C}$., warmed in water, then emptied in either the horizontal or the vertical position, after agitation in four instances. Evidence of separation was obtained from the eight cylinders which were not agitated (Table I).

\begin{tabular}{|c|c|c|c|c|}
\hline Size of Cylinder & $\begin{array}{c}\text { Temp. at } \\
\text { Start of } \\
\text { Withdrawal } \\
\text { of Mixture } \\
\left.{ }^{\circ} \mathrm{C} .\right)\end{array}$ & $\begin{array}{l}\text { Position of Cylinder } \\
\text { during Emptying }\end{array}$ & $\begin{array}{c}\text { Cylinder } \\
\text { Agitated (+) } \\
\text { or Not (-) }\end{array}$ & $\begin{array}{c}\text { Layering } \\
\text { Present }(+) \\
\text { Absent }(-)\end{array}$ \\
\hline 2,0001 & $\begin{array}{l}22.7 \\
16.8 \\
21.0 \\
17.8 \\
24.4 \\
28.4 \\
13.1 \\
13.9 \\
17.4 \\
15.5 \\
11.2 \\
15.9\end{array}$ & $\begin{array}{c}\text { Vertical } \\
\text { ", } \\
\text { ", } \\
\text { Horizontal } \\
\text { Vertical } \\
\text { ”, } \\
\text { Horizontal } \\
, "\end{array}$ & $\begin{array}{l}+ \\
\pm \\
= \\
= \\
+ \\
\pm \\
= \\
= \\
-\end{array}$ & $\begin{array}{l}- \\
\pm \\
+ \\
+ \\
+ \\
\pm \\
\pm \\
+ \\
+ \\
+ \\
+\end{array}$ \\
\hline
\end{tabular}

Twelve of the cylinders investigated in the present study were found towards the end of the emptying period to deliver a mixture containing less than $21 \%$ oxygen; of these cylinders 10 were vertical and two horizontal (Fig. 4). The maximum volume of this oxygen-poor mixture obtained from a large cylinder was 140 litres, and the maximum volume obtained from a small cylinder was 120 litres.

\section{Changes in Temperature During Emptying}

At all the sites monitored the temperature was found to drop markedly during emptying of the cylinder, whether precooled or not (Fig. 5). The greatest and most precipitous falls were observed on the demand-valve. Here the temperature fell to between -26 and $-28^{\circ} \mathrm{C}$. during the continuous emptying of

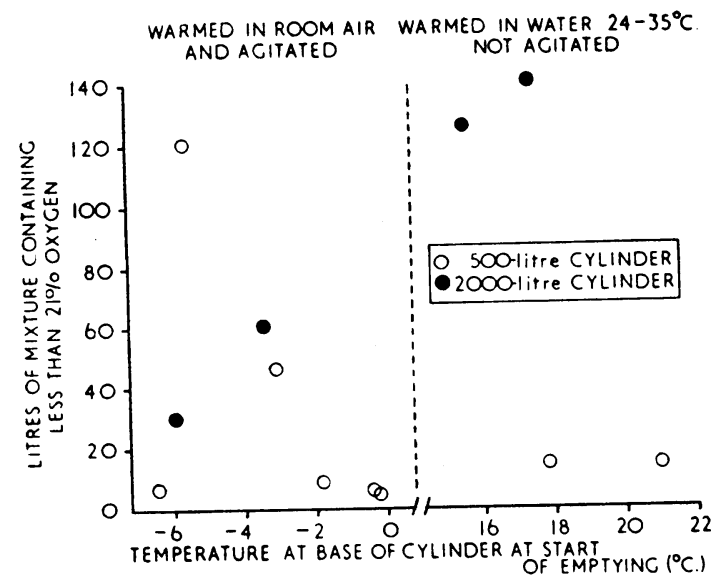

FIG, 4-A mixture containing less than $21 \%$ oxygen was obtained from 12 cylinders, each of which had been cooled to the from 12 cylinders, $-20^{\circ} \mathrm{C}$. Eight of the cylinders were agitated after rewarming in air; four were placed in water $\left(24-35^{\circ}\right.$ C.) for five minutes and not agitated before being emptied. Details of the degrees of rewarming and of the volumes of oxygen-poor mixture have been plotted. cylinders cooled before the run. The fall in temperature was less marked when the cylinders were emptied by intermittent demand. The minimum temperature on the demand-valve was attained usually when the cylinder had been one-third to one-half emptied, and thereafter the demand-valve steadily grew warmer (Fig. 5).

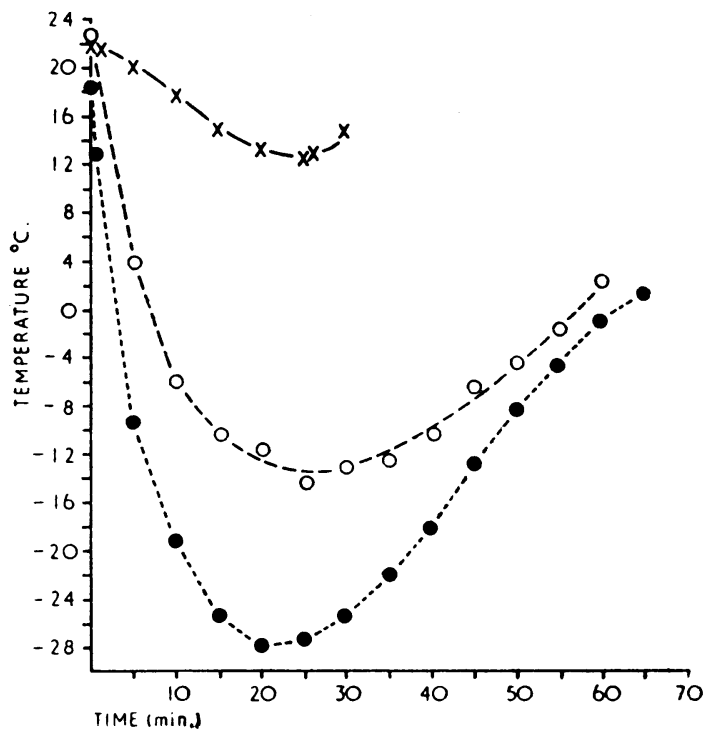

FIG. 5.-Typical recordings of temperature changes observed during the course of emptying a full cylinder. The upper curve $(x-x)$ refers to the temperature of the emergent gas mixture from a 500-litre cylinder which had not been precooled (temperature at start of which has run $21.3^{\circ} \mathrm{c}$.) and was emptied contre at 16 per minute). The middle curve (O) relates to the temperature of the due course of emptying a 2,000-ifre cylinder (not precooled, initial temperature $22.3^{\circ}$ C.) continuously (1 litre at 30 per minute). The lowest curve (---) depicts the temperature of the demand-valve as a precooled 2,000-litre cylinder (initial temperature $8.6^{\circ} \mathrm{C}$.) was emptied continuously ( 1 litre at 30 per minute).

The temperature of the emergent gases was measured during seven runs. During four of these, involving continuous demand from small cylinders, a steady drop in temperature was observed throughout. During other runs (two large cylinders emptied intermittently and one small emptied continuously) the temperature began to rise again towards the end of the run (Fig. 5).

Almost invariably the temperature of the cylinder fell during the period of emptying, irrespective of the initial temperature. Most frequently a sharp fall occurred during the early minutes, followed by a more gradually progressive decline, and as the run neared completion a slight rise was observed. Minor variations of this pattern were common, and on two occasions the temperature of the cylinders (both large) rose steadily (from an initial -4.9 and $-1.5^{\circ} \mathrm{C}$. respectively) throughout the run.

Two additional observations are worth reporting. Firstly, a marked fall of temperature during the final minutes of emptying (irrespective of whether the temperature had previously been rising or falling) occurred when evidence of variations of composition of the emergent mixture had been obtained. Secondly, the temperature of the cylinder often dropped by 3 to $4^{\circ} \mathrm{C}$. during agitation.

Despite the fact that the temperature of the cylinder often fell to below $-8^{\circ} \mathrm{C}$. during the course of emptying, and the fact that considerable frosting developed on the cylinder surface, no change in composition of the emergent gas mixture referable to the cooling associated with emptying was observed.

\section{Performance of the Demand-valve}

Despite the marked range of temperature change to which it was subjected, the Entonox demand-valve appeared to fulfil its 
function satisfactorily. On three occasions gas escaped between demand periods, but this minor fault was rapidly corrected by momentarily disengaging the tubing from the Entonox head.

\section{Meteorological Data}

Table II shows the number of times during the period 1961-5 when the monthly minimum temperature recorded in several heavily populated areas fell below $-7^{\circ} \mathrm{C}$.

TABLE II.-Number of Months During 1961-5 in Which Minimum Temperature Recorded at Places Named in Column 1 Fell to a Value Indicated in Other Columns. The Individual Value Recorded When Temperature was Below $-8^{\circ} \mathrm{C}$. is Noted in Final Column. Data Provide no Information Regarding Number of Times Daily Tem perature was Recorded as Being Only Slightly Higher than Minimum Value of Month in Question

\begin{tabular}{|c|c|c|}
\hline \multirow[t]{2}{*}{ Place } & \multicolumn{2}{|c|}{$\begin{array}{c}\text { No. of Months During which the Minimum } \\
\text { Temperature was }\end{array}$} \\
\hline & -7 to $-8^{\circ} \mathrm{C}$ & Below $-8^{\circ} \mathrm{C}$ \\
\hline Aldergrove (Belfast) & 0 & $6(-10.7,-9.4,-8.9,-10.6$, \\
\hline Elmdon (Birmingham) .. & 1 & $\begin{array}{r}12(-10 \cdot 2,-8 \cdot 2,-10 \cdot 7,-16 \cdot 0, \\
-11 \cdot 8,-8 \cdot 0,-13 \cdot 5,=11 \cdot 6, \\
-9 \cdot 5,-8 \cdot 2,-11 \cdot 6, \text { and }-10 \cdot 1)\end{array}$ \\
\hline $\begin{array}{l}\text { Kew } \\
\text { Renfrew (G̈lasgoö) }\end{array}$ & $\begin{array}{l}0 \\
4\end{array}$ & $\begin{array}{l}1(-9 \cdot 7), \\
6(-9 \cdot 8, \quad-9 \cdot 1, \quad-13 \cdot 8,-8 \cdot 7 \text {, } \\
\quad-12 \cdot 5, \text { and }-8 \cdot 4)\end{array}$ \\
\hline Ringway (Manchester) .. & 3 & $5(-9.1,-10.0,-9.7,-11.4$, \\
\hline 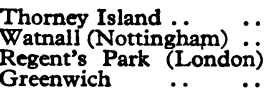 & $\begin{array}{l}0 \\
4 \\
1 \\
2\end{array}$ & $\begin{array}{l}2(-9 \cdot 2 \text { and }-9 \cdot 1) \\
2(-12 \cdot 8 \text { and }-10 \cdot 6) \\
1(-11 \cdot 1) \\
1(-12 \cdot 2)\end{array}$ \\
\hline
\end{tabular}

\section{Discussion}

The first result of importance in this series of experiments on premixed gases was the observation that even when the mixture emerging from a cylinder was constant the nominal $50 / 50$ nitrous oxide and oxygen mixture contained an oxygen concentration which varied between 48 and $56 \%$ from cylinder to cylinder (Fig. 1). Though such variations are unlikely to have any great clinical significance when the gas mixture is inhaled, the observation is important because of the effect of such variations on the critical temperature of the mixture.

The critical temperature of a gas is that temperature above which the gas cannot be liquefied by pressure alone. In the case of the 50/50 nitrous oxide and oxygen mixture a critical temperature of $-7^{\circ} \mathrm{C}$. has been quoted (Gale et al., 1964), but the behaviour of the mixture at this temperature is not typical of a normal gas, since on rewarming it does not necessarily revert to a homogeneous gas mixture. For convenience in discussion, however, the term "critical" will continue to be used when referring to the nitrous oxide and oxygen mixture. Because the critical temperature of the mixture is related to the partial pressure of its components and to their individual critical temperatures, it follows that any change in the composition of the nitrous oxide and oxygen mixture will alter its critical temperature. Moreover, since the critical temperature of nitrous oxide is $36.5^{\circ} \mathrm{C}$. and that of oxygen $-118.8^{\circ} \mathrm{C}$., it follows that in any mixture of these gases the critical temperature will be increased as the percentage of nitrous oxide is increased; if on the other hand the oxygen present is increased the critical temperature must fall.

The importance of this temperature effect is underlined by the results obtained from the experiments on cylinders which had been previously cooled and then rewarmed. In these experiments it was shown that once a full cylinder had been cooled below the critical temperature the emergent mixture was not always constant even when rewarming had taken place. In these circumstances the concentration of oxygen in the mixture withdrawn from the cylinder was initially relatively high, but it gradually fell as emptying continued. Indeed, 12 of the cylinders tested delivered an oxygen concentration of less than $21 \%$ in the later stages of emptying, and in one instance the final 120 litres discharged from a cylinder of 500 litres capacity contained less than $21 \%$ oxygen. The potential danger of such a situation in clinical practice is obvious.

So far as is known this effect can be explained only by partial separation within the cylinders of the component gases of the mixture. This interpretation is supported by the fact that adequate rewarming followed by agitation restores the homogeneity of the mixture (Fig. 3).

These results support the earlier work of Tunstall (1963) and that of Cole (1964), both of whom demonstrated a similar lack of homogeneity in the mixtures issuing from full cylinders after cooling. Gale et al. (1964), however, claimed that in cylinders cooled to $-8^{\circ} \mathrm{C}$. separation of the components of the mixture does not occur until the pressure within the cylinder has fallen to 48 atmospheres (705 lb./sq. in. ; $49.5 \mathrm{~kg}$./sq. cm.). But their evidence hardly substantiates this claim, and in the light of our experience their assertion that Cole (1964) could not have been using cylinders filled to 101 atmospheres $(1,480 \mathrm{lb}$./sq. in. ; 104 $\mathrm{kg} . / \mathrm{sq}$. cm.) at $-8^{\circ}$ C. seems difficult to justify.

The argument is not merely academic. Table II shows that during 1961-5 the temperature fell below $-7^{\circ} \mathrm{C}$. on 13 occasions in the Birmingham area, on 10 occasions in Glasgow, and on eight in Manchester. Thus the opinion of Gale et al. (1964) that conditions leading to partial stratification of the constituent gas in a 50/50 nitrous oxide and oxygen mixture were unlikely to occur in practice is not in accordance with the facts. Furthermore, if cylinders during distribution are exposed on a moving vehicle during bad weather conditions their surface temperatures may fall below the critical level even when the environmental temperature at the destination is substantially higher.

Unfortunately, the identification of cylinders exposed to low temperatures is virtually impossible unless the history is known, and, though the possibility of using a temperature-sensitive paint is being explored, the only safe policy at the moment is to regard every cylinder containing premixed nitrous oxide and oxygen as potentially dangerous during the winter months. Under present conditions the onus is surely on the supplier to deliver the gas mixture in a homogeneous state; the responsibility of the medical and nursing staff is to ensure that the homogeneity of the mixture is preserved before administration to a patient.

The need for a satisfactory method of administering a 50/50 nitrous oxide and oxygen mixture is obvious, and it would be unfortunate if the undoubted advantages of this system fell into disrepute because of handling or administrative difficulties.

\section{Summary}

Eighty cylinders containing a 50/50\% nitrous oxide and oxygen mixture were allowed to discharge through an Entonox demand-valve. The consentration of oxygen in the emergent mixture was recorded from 70 of these. On 36 occasions this mixture was constant throughout, but the oxygen concentration varied from cylinder to cylinder between 48 and $56 \%$. During the remaining 34 runs there was evidence of partial separation of the components of the mixture; this occurred in full cylinders which had been cooled below the critical temperature and not adequately rewarmed before agitation. In 12 cylinders gas mixtures containing less than $21 \%$ oxygen were obtained, and on one occasion the oxygen concentration fell to $4 \%$. The volume of this hypoxic mixture was variable, but in one instance the final 120 litres withdraxn from a small cylinder were hypoxic.

Meteorological data show that monthly minimum temperatures below the critical temperature were observed 31 times 
during 1961-5 in the densely populated areas of Birmingham, Glasgow, and Manchester. Adequate precautions taken during the handling of cylinders, both at the time of distribution and before use, can ensure safety in the use of $50 / 50 \%$ nitrous oxide and oxygen mixture.

We are indebted to the British Oxygen Company for supplying the Entonox demand-valve and a generous supply of cylinders. We are also indebted to the Meteorological Office, whose records provided the basis for Table II.
REFERENCES

Cole, P. V. (1964). Anaesthesia, 19, 3

and Nainby-Luxmore, R. C. (1962). Ibid., 17, 505.

Gale, C. W., Tunstall, M. E., and Wilton-Davies, C. C. (1964). Brit. med. 7., 1,732 .

Hill, D. W., Hook, J. R., and Bell, E. G. (1961). F. sci. Instrum., 38

Lancet, 1965, 1, 1229

Lair, D. D., and Bisset, W. I. K. (1965). F. Obstet. Gynaec. Brit. Cwlth, 72, 264 .

Nainby-Luxmore, R. C. (1964). Anaesthesia, 19, 421

Tunstall, M. E. (1961). Lancet, 2, 964

Tunstall, M. Brit. med. F., 2, 915 .

\title{
Methotrexate in Treatment of Sarcomata
}

\author{
E. WILTSHAW,* M.B., B.CH.
}

Chemotherapeutic agents are so commonly used in the treatment of widespread malignant disease that it is unlikely that any tumour has escaped a trial of cytotoxic drugs. However, in some of the rarer tumours, including the connective-tissue sarcomata, no proper assessment of the value of chemotherapy can be made, because reports are based on the treatment of a few or even single cases. In 1960 we treated a patient suffering from fibrosarcoma of the bladder with a combination of chlorambucil, methotrexate, and one dose of actinomycin D (Case 1). The regression which followed was dramatic ; but the toxic manifestations were severe: some features of this response suggested that methotrexate was the effective agent. Subsequently, therefore, patients suffering from soft-tissue sarcomata beyond the scope of surgery or radiotherapy were treated with methotrexate. This paper reports the results in leiomyosarcoma, fibrosarcoma, and undifferentiated sarcoma.

\section{Patients Treated}

Between 1 March 1960 and 30 September 196532 patients were treated. There were 15 cases of leiomyosarcoma, eight of fibrosarcoma, and nine of undifferentiated sarcoma.

The effect of chemotherapy could not be assessed in seven cases. One patient had no palpable tumour when treatment was begun, though a fibrosarcoma had been found during operation and was only partially removed. Three patients were lost to follow-up (two cases of leiomyosarcoma and one of undifferentiated sarcoma). Finally, three patients died within 14 days of starting chemotherapy (two cases of leiomyosarcoma and one of undifferentiated sarcoma). The results in the remaining 25 patients are reported here (see Table I).

Three patients were treated for inoperable primary tumours, 16 for local recurrence of tumour with or without metastases, and six for generalized disease but with no local recurrence. Histological specimens were reviewed in all the cases.

\section{Method of Treatment}

All the patients received methotrexate orally. Intravenous injections were also given if the patient was vomiting or there were doubts about absorption of the drug. From 2.5 to $10 \mathrm{mg}$. was given daily in divided doses by mouth for 2 to 15 days. One patient (Case 9) had a single oral course of $5 \mathrm{mg}$. daily for 45 days. This patient also received an intra-arterial infusion. The remaining patients received 2 to 29 courses.

* Chester Beatty Research Institute, London S.W.3.
The daily dose and the duration of each course of drug were regulated according to the side-effects produced and were not calculated on the basis of body weight. Commonly, five-day courses were planned at $10 \mathrm{mg}$. daily, but were often cut short by soreness of the mouth, frank ulceration, nausea or vomiting, and occasionally by leucopenia. The next course was begun when the toxic effects had disappeared, or within six weeks. The time between courses varied from four days to six weeks (commonly every two weeks), and courses were given less frequently as the patient improved. Intra-arterial and intravenous therapy were given by continuous infusion over a period of 8 to 24 hours in doses of 10 to $25 \mathrm{mg}$. daily until evidence of toxicity appeared. This took two to three days in the case of intravenous infusions, and five days in the one case of intraarterial infusion.

\section{Side-effects and Toxicity}

Anorexia was a common side-effect (11 patients) and tended to be more troublesome during successive courses. Two of the 11 patients vomited at the end of each course of methotrexate. Oral ulceration was seen in 18 cases; it occurred at the end of a course, or in the three days after the last dose of the drug. Six did not have ulceration, and one had so much tumour in the mouth that other oral lesions could not be recognized. Though five-day courses of therapy were planned, many patients could not tolerate more than three days' treatment, and a few could accept only two-day courses of 5 to 10 mg. The duration of the courses and the daily dose of the drug were regulated for each patient so that he had as few side-effects as possible. The first symptom of oral toxicity was a slight soreness in the mouth, usually on the inner side of the lips or tongue. The earliest sign was a local erythema of the mucous membrane. Frank ulceration would often develop in this area within 24 hours.

The effect of methotrexate on the peripheral blood was sometimes severe and rapid. The effect on the blood count was recorded as "severe" if the haemoglobin concentration fell $3 \mathrm{~g}$. $/ 100 \mathrm{ml}$. or more, if the total leucocyte count fell by $50 \%$ or more, and the platelet count fell by $50 \%$ or more after the first course of the drug. A severe fall in the haemoglobin was seen in 10 cases, of the white cell count in 15 , and of the platelet count in eight. The effect on the peripheral blood was usually less with successive courses of therapy, but in one instance a single intravenous dose of methotrexate in a patient with severe renal damage caused marrow aplasia and death. The only other side-effect of treatment was mild partial alopecia in two patients. 